Intergroup relations are more competitive and discordant than relations between interacting individuals. Social identity theory suggests that this discontinuity should be greatest among individuals who identify strongly with their in-group. To test this prediction, students from countries with collectivistic and individualistic cultures completed a measure of self-construal. They were then asked to identify how they would respond to a conflict, either with another individual, between their group and another group or between their country and another country. Participants responded more negatively to intergroup and international conflicts than to interpersonal conflicts. Self-construal, however, moderated this effect. Controlling for country of origin, students who were high in interdependence endorsed threat more and acceptance of the others' demands less in an international conflict versus an interpersonal conflict. Those low in interdependence differed less in their endorsement of conflict resolution strategies in an international versus an interpersonal conflict.

\title{
INTERDEPENDENT CONSTRUAL OF SELF AND THE ENDORSEMENT OF CONFLICT RESOLUTION STRATEGIES IN INTERPERSONAL, INTERGROUP, AND INTERNATIONAL DISPUTES
}

\author{
VALERIAN J. DERLEGA \\ Old Dominion University \\ CEM SAFAK CUKUR \\ University of Nebraska at Lincoln \\ JENNY C. Y. KUANG \\ Old Dominion University \\ DONELSON R. FORSYTH \\ Virginia Commonwealth University
}

Insko, Schopler, and their colleagues, in a series of studies, have documented the discontinuity effect: the tendency for people to be more competitive in intergroup situations compared to situations involving one-to-one interaction (see Insko \& Schopler, 1998, for a summary). Insko and Schopler (1998) suggested that this effect occurs when group members shift toward greater competitiveness when they discover that others in the group also favor the competitive, group-centered choice. They also note that individuals fundamentally distrust groups and so respond more negatively because they expect the other party to compete rather than cooperate. This discontinuity may, however, also be partly rooted in the collective identities of group members. Unlike single individuals interacting with other single individuals, members of groups share a common social identity, and their greater competitiveness and hostility may serve to protect and extend that collective self (Tajfel \& Turner, 1979).

Here we examine this social identity analysis by determining if the discontinuity effect is related to culture-linked variations in self-construal. Extending the work of Markus and Kitayama (1991), Singelis (1994), and others (see Howard, 2000), we predicted that the

AUTHORS' NOTE: Correspondence about this article should be sent to Valerian J. Derlega, Psychology Department, Old Dominion University, Norfolk, VA 23529-0267 (e-mail: vderlega@ odu.edu), or to Cem Safak Cukur, who is now affiliated with the Psychology Department, Mugla University, Mugla, Turkey (e-mail: cemsafak@yahoo.com).

JOURNAL OF CROSS-CULTURAL PSYCHOLOGY, Vol. 33 No. 6, November 2002 610-625

DOI: $10.1177 / 0022022102238272$

(c) 2002 Western Washington University

610 
discontinuity effect would be more likely to occur among individuals whose interdependent self-construals emphasize the collective self rather than the personal, individualistic self. Because we tested this prediction with a sample of international and American-born students at a U.S. university, we also examined the relationship between country of origin and selfconstrual and the separate contributions of self-construal and country of origin to the discontinuity effect. Before describing the research, we will review previous literature on the discontinuity effect as well as on the culture-linked aspects of personality that may affect coping with conflict in different social situations.

\section{THE DISCONTINUITY EFFECT}

Insko, Schopler, and their colleagues called the tendency for groups to respond more competitively than individuals the discontinuity effect because the competitiveness between members of groups is out of proportion to the competitiveness displayed by individuals when interacting with other individuals (Insko \& Schopler, 1998; Insko, Schopler, Hoyle, Dardis, Graetz, 1990; Schopler \& Insko, 1992). When they arrange for individuals and groups to play the Prisoner's Dilemma game (a mixed-motive game involving a combination of cooperative and competitive elements) against other groups and individuals, they repeatedly find that participants who are members of a group playing against another group- the intergroup condition-are more competitive and less cooperative than single individuals playing against other single individuals (the interpersonal condition).

Insko and Schopler (1998) have identified a number of personal and interpersonal factors that contribute to the discontinuity effect. Their greed hypothesis suggests that the members of interacting groups support each other's selfishness, and as a result, competition increases and cooperation decreases. Their identifiability hypothesis argues that the anonymity of the group situation frees members to make more competitive choices. Their distrust hypothesis suggests that groups may be more competitive than individuals are in interpersonal situations because they expect that intergroup relations are more unfriendly, threatening, and aggressive. Consistent with this final hypothesis, Hoyle, Pinkley, and Insko (1989) found that individuals rate intergroup interactions more negatively on trait adjectives such as more competitive and domineering, whereas they rate individual (i.e., one-on-one) interactions more positively on trait adjectives such as trustworthy and cooperative.

\section{SOCIAL IDENTITY AND INTERGROUP CONFLICT}

Interpersonal models of the self suggest a different, though closely related, explanation for the discontinuity effect. This theoretical perspective, although consistent with a number of models of the self, is expressed most clearly in Tajfel's social identity theory (e.g., Tajfel, 1982) and Turner's self-categorization theory (e.g., Turner \& Onorato, 1999). Tajfel (1982) defined social identity as "that part of the individual's self-concept which derives from their knowledge of their membership in a social group (or groups) together with the value and emotional significance attached to the membership" (p. 2). The theory assumes that individuals' self-related cognitions and actions reflect the social categories they identify with and that they maintain their self-esteem by reaffirming the value of these collectives and by differentiating these groups from other groups. These identity processes result in various intergroup biases: Members tend to favor their group, its members, and its products while derogating other groups, their members, and their products (Brewer \& Brown, 1998; Tajfel \& Turner, 1979). 
Tajfel and Turner (1979) demonstrated the pervasiveness of the intergroup bias in their minimal group experiments. Even when individuals were classified into temporary groups arbitrarily, they nonetheless favored members of the in-group over the out-group. Other researchers, however, have reported that intergroup biases become more pronounced when group members strongly identify with the in-group and when the relative status of the two groups is salient. Duckitt and Mphuthing (1998), for example, reported that Black Africans' attitudes toward an out-group (Afrikaans Whites) were negatively associated to the strength of their in-group identification. Brown, Maras, Masser, Vivian, and Hewstone (2001) found that Britons' attitudes toward the French were negatively correlated with the strength of their British identities. Brown, Hinkle, and their colleagues also found that in-group identification was correlated with intergroup biases but only in collectivistic, relational contexts (Brown et al., 1992; Hinkle \& Brown, 1990). Brown et al. (1992) classified group members as individualists or collectivists and also assessed the extent to which they stressed outperforming other groups (a "relational orientation") or evaluation based on an asocial standard (an "autonomous orientation"). They report that group identification was highly correlated with intergroup biases $(r=.55)$ for relational collectivists, lower ( $r \mathrm{~s}=.23$ and .24 , respectively) for autonomous collectivists and relational individualists, and nonsignificant $(r=.05)$ for autonomous individuals.

\section{INTERDEPENDENT AND INDEPENDENT SELF-CONSTRUALS}

When do individuals identity strongly with their groups? Individuals may differ in their collective thoughts and feelings based on the culture in which they are raised (e.g., Leung, 1987, 1988; Markus \& Kitayama, 1991, 1994; Oyserman, 1993; Singelis, 1994; Triandis, Bontempo, Villareal, Asai, \& Lucca, 1988; Triandis, McCusker, \& Hui, 1990). The cultures of many Asian, Latin American, Eastern European, and Middle Eastern countries, for example, emphasize that individuals should value interdependence and group solidarity. On the other hand, the cultures of countries in Western Europe, the United States, Canada, and Australia emphasize that individuals should value independence and emotional detachment from one's groups and that personal goals should have priority over group goals. The distinction between countries in terms of how much emphasis different cultures place on the individual's identification and commitment to the in-group is labeled collectivism versus individualism (e.g., Hofstede, 1980; Triandis, 1995).

The cultural concept of individualism-collectivism has been widely used to explain differences in behavior between cultural groups. However, researchers have argued that individual- (or psychological-) level variables are necessary to understand differences in behavior between cultures (Kagitcibasi, 1994; Kim, 1994; Singelis, 2000; Singelis, Bond, Sharkey, \& Siu Yiu Lai, 1999; Triandis, 1995). An important approach to understanding culture-linked individual differences is represented by the work of Markus and Kitayama (1991) on two personality dimensions: the independent and interdependent construals of self.

An independent self-construal, according to Markus and Kitayama (1991), emphasizes that the self is "bounded, unitary, [and] stable" (p. 230). The self is perceived as separate from others, and one is concerned about achieving and/or promoting personal rather than others' interests and needs. On the other hand, an interdependent self-construal emphasizes a "flexible, variable" self (p. 230) that focuses on fulfilling social obligations and subordinating personal goals in favor of the needs of one's in-group. Individuals might have independent and interdependent self-images of varying strength, but collectivistic cultures emphasize 
the development of an interdependent construal of self, and individualistic cultures emphasize the development of an independent construal of self (Singelis, 1994, 2000; Singelis et al., 1999).

A collectivistic self-construal may contribute to the discontinuity effect both by limiting interpersonal conflict between in-group members and by exacerbating intergroup conflict. Markus and Kitayama (1991) noted that in mostly collectivistic cultures, there is an emphasis on inhibiting the expression of anger as a way of promoting harmony and solidarity within the in-group. Individualistic cultures, in contrast, do not inhibit the expression of hostility in different social contexts (that is, in interactions between individuals or between groups) because individuals are allowed to pursue their self-interests and "confrontation is OK." This preference for harmony-enhancing strategies may not extend to members of the out-group (e.g., Leung, 1987; Leung, Au, Fernandez-Dols, \& Iwawaki, 1992; Leung, Bond, Carment, Krishnan, \& Liebrand, 1990; Leung \& Lind, 1986). Research suggests that the expression of anger may be more likely in confrontations with members of an out-group in collectivist cultures because there is no bonding or sense of solidarity with them. Leung (1988), for example, asked residents of Hong Kong (considered to be a more collectivistic culture) and the United States (considered to be a less collectivistic culture) to read about a dispute over the sale of a defective household appliance and judge the likelihood of the buyer's suing the seller. Leung found that the Chinese and the Americans did not differ when considering suing a friend (an in-group member), but the Chinese were significantly more likely than the Americans were to prefer suing a stranger (an out-group member). Also, on a personality measure of interdependence (Hui's [1988] collectivism scale), higher ratings of interdependence for both the Hong Kong and the American participants were associated with a higher likelihood of suing a stranger but not friend.

\section{THE CURRENT STUDY}

We have described how individuals are more competitive and more aggressive in intergroup than in interpersonal conflict situations-what is called the discontinuity effect. But rather than tracing this tendency to individuals' general distrust of groups, we suggest that the discontinuity effect reflects intergroup biases associated with social identity processes. During interpersonal conflicts—single individuals competing against other single individuals-responses are dictated by personal motives. But when members of intact groups compete against other groups, these individual motives are buttressed by collective motives. In consequence, and particularly when members identify strongly with their group, conflict between groups is likely to be more competitive and hostile than is conflict between individuals.

We tested this conceptualization by measuring the self-construals of students from countries with collectivistic and individualistic cultures and asking them how they would respond to several types of conflicts. Rather than using the gaming procedures developed by Insko and Schopler (1998) in their studies of discontinuity, we instead used role-play procedures based on Betz and Fry (1995). These investigators asked participants to imagine being in a conflict involving either two persons (an interpersonal conflict), two groups (an intergroup conflict), or two countries (an international conflict). Integrating their methods with those used by Gire and Carment (1992), we then offered participants a choice among various ways of dealing with the conflict, including ones that would stimulate conflict escalation (threat and avoidance) and ones that would likely reduce conflict (negotiation, mediation, and acceptance of the other party's position). 
First, drawing on studies of the discontinuity effect and Betz and Fry's (1995) findings, we predicted that participants would be more likely to endorse the use of divisive tactics in the intergroup or international conflict conditions than in the interpersonal conflict condition. Next, we predicted that participants' endorsements of the different modes of conflict resolution would differ in relationship to the level of interdependence of their self-construals and the type of conflict they were facing. When conflicts pitted one group against another, we predicted that individuals who were high in interdependence would be more likely to endorse conflict-enhancing techniques (threat and avoidance) and less likely to endorse conflict-reducing techniques (negotiation, mediation, and acceptance of the other party's position). Participants who were low in interdependence would be less likely to differ in their endorsement of conflict-coping strategies as a function of the type of conflict. We predicted that research participants who were high, compared to low, in interdependence would experience more negative feelings in intergroup or in international conflicts than in interpersonal conflicts. We based this prediction on the idea that the expression of negative feelings may be more acceptable (Markus \& Kitayama, 1991) and more likely to occur with people who are seen as different from oneself.

We also predicted that individual differences in interdependence would be most strongly associated with reactions to international conflicts rather than intergroup conflicts. We based this prediction both on the assumption that participants' social identities would be more strongly associated with their nationalities than with their memberships in time-limited, voluntary groups and on the assumption that elements of interpersonal conflict (one-to-one interaction) would likely be present when small groups interact with other small groups.

Although we expected that individuals whose country of origin was collectivistic would construe their self as more interdependent than independent, we predicted that the interdependent construal of self would explain reactions to conflict even when country of origin was controlled for statistically.

We did not formulate any specific hypotheses about how individual differences in independence would moderate how one copes with conflict in different types of social situations. A study by Oyserman (1993) found that Arab and Jewish Israelis who were high, compared to those who were low, in independence had a heightened awareness of group conflict between Arabs and Jews. Oyserman suggested that the independent construal of self may increase attention to group conflict in an ethically divided community. Nevertheless, we had no basis to predict differences in the endorsement of conflict-enhancing or conflict-reducing techniques in interpersonal, intergroup, and international disputes as a function of the independent construal of self. Nor did we expect that research participants who were high in the independent construal of self would experience differences in negative affect as a function of the type of conflict situation.

\section{METHOD}

\section{PARTICIPANTS}

A total of 306 men and women participated in the study. All were students at Old Dominion University in Norfolk, Virginia. The sample included American (from a predominantly individualistic culture) and international students (from predominantly collectivistic cultures, including Arab-speaking countries, China, India, Greece, Japan, Korea, Russia, Thailand, and Turkey). There were 62 men and 91 women in the American-born group, and there 
were 80 men and 73 women in the foreign-born group. The American participants were recruited via an announcement to students in psychology classes. The international students were recruited via an announcement to students at the international student association on the campus. The idea of recruiting both American and international students for the study was to include research participants from different cultural backgrounds, which would increase the possible range of scores on the culture-linked personality variables of interdependence and independence and broaden the generalizability of the findings.

\section{MATERIALS}

Conflict stories and rating scales for the conflict resolution strategies. Each participant was given a packet of materials that included one of nine stories. The type of conflict independent variable manipulation (based on the specific story read by participants) reflected a conflict either between the research participant and another person (a classmate or a neighbor), between the research participant's group (a campus group, an investment group, or a group that manages a summer camp) and another group, or between the research participant's country and another country. The other party in the dispute (another person, group, or country) was always depicted as having initiated the conflict. Based on the type of conflict represented in the stories, $A$ was used to identify the research participant, his or her group, or his or her country, whereas $B$ was used to identify the other person, the other group, or the other country. The stories were counterbalanced in terms of what resource was in dispute: a disagreement over money, land boundaries, or water use. We do not report the results according to the type of resource involved in the dispute. The impact of the nature of the resource under dispute was not of theoretical interest for this research, and examining these effects would have added to an already complex statistical design. The stories were adapted, with minor changes, from stimulus materials developed by Betz and Fry (1995).

After reading one of the possible stories, research participants rated their likelihood of using each of five techniques (adapted from Gire \& Carment, 1992; Leung, 1987) to resolve the dispute. The tactics were threat ("You would threaten the other party and say that you would publicize their action and thus damage their image and reputation"), accept the situation ("You would accept the situation as it is, that is, you would yield to arguments of the other party"), negotiate ("You would negotiate with the other party hoping that you both would compromise to reach a solution acceptable to both parties"), seek the assistance of a third party ("You would seek the assistance of a third party, hoping to find a mediator who will assist in the negotiation; that is, you would try to reach a settlement by following the mediator's guidance"), and ignore the other party ("You would ignore the other party; that is, you would leave the scene and avoid contact with the other side again"). Participants' endorsement of these tactics was made on 7-point scales ranging from 1 (extremely likely to use) to 7 (not likely to use at all). For ease of description of the results, scores on the tactic scales were reversed in the data analyses so that a higher score reflected a higher endorsement of a conflict tactic. We assumed that threat and avoidance are conflict-enhancing strategies, whereas accept the situation, negotiate, and mediate via seeking the assistance of a third party are conflict-reducing strategies.

Affect measures. Next, research participants completed a mood inventory that asked them how they would feel if they were in the dispute described in the story. Recall that participants were asked to imagine that the other party had initiated the dispute. Negative and positive 
emotions, respectively, were measured using the Positive and Negative Affect Scale developed by Watson, Clark, and Tellegen (1988). The positive and negative affect scales each contain 10 items. Typical positive mood items include interested, excited, enthusiastic, proud, alert, and active. Typical negative mood items include distressed, guilty, scared, and nervous. Participants' responses to the mood items were made on 7-point scales ranging from 1 (extremely) to 7 (not at all). These ratings were reverse scored in the data analyses. The coefficient alphas for negative affectivity were .81 and .76 for the international and the American students, respectively. The coefficient alphas for positive affectivity were .68 and .84 for the international and the American students, respectively.

Self-Construal Scale. Then research participants completed the 24-item Self-Construal Scale (Singelis, 1994) measuring the culture-linked personality variables of interdependence and independence. The interdependent items focus on placing priority on in-group rather than personal goals. Typical items include "It is important to me to respect decisions made by the group" and "I will stay in a group if they need me, even if I' $m$ not happy with the group." The independent items focus on placing priority on achieving personal goals. Typical items include "I prefer to be direct and forthright when dealing with people I've just met" and "My personal identity independent of others is very important to me." The participants' responses on the interdependence and independence scales were made on 7-point scales ranging from 1 (extremely) to 7 (not at all). These ratings were reversed in the data analyses so that higher scores on interdependence and independence reflect a greater endorsement of these personality traits. The coefficient alphas for the subscale measuring the interdependent construal of self were .64 and .59 for the international and the American students, respectively. The coefficient alphas for the subscale measuring the independent construal of self were .50 and .61 for the international and the American students, respectively. These reliability estimates are less than ideal, reflecting perhaps the difficulty in the measurement of independence and interdependence in cross-cultural research (Singelis, Triandis, Bhawuk, \& Gelfand, 1995). Nevertheless, they provide some evidence for the consistency of the measures. The correlation between the interdependence and the independence scales was -.02 . This latter finding supports the view (Singelis, 1994) that the dimensions of independent and interdependent self-construals are orthogonal.

\section{RESULTS}

\section{CULTURE AND SELF-CONSTRUALS}

A comparison of the international- versus the American-born research participants provided support for the construct validity of the interdependence and the independence scales by replicating prior studies of international differences in cultural orientations. A 2 (country of origin: United States vs. international) $\times 2$ (gender) ANOVA for the interdependence and independence scales yielded only main effects of nationality, $F \mathrm{~s}(1,302)=69.57$ and 26.55 , respectively, $p s<.001$. The international $(M=5.09, S D=0.86)$, compared to the American $(M=4.32, S D=0.77)$, students scored higher, on the average, on the interdependence scale. On the other hand, the American $(M=5.13, S D=0.74)$, compared to the international $(M=$ $4.70, S D=0.75$ ), students scored higher, on the average, on the independence scale. These results are consistent with descriptions of individuals from predominantly collectivistic countries (e.g., Arab-speaking countries, Japan, and Turkey) as interdependent and indi- 
viduals from predominantly individualistic countries (e.g., the United States) as independent (Markus \& Kitayama, 1991; Singelis, 1994).

\section{DISCONTINUITY IN REACTIONS TO CONFLICTS}

To examine participants' reactions to the three types of conflict-interpersonal, intergroup, and international - we conducted a 3 (conflict type) X 2 (gender) ANOVA for the five types of conflict management strategies and the two types of affect. The significant main effects of conflict type on the conflict management strategies were generally consistent with expectations about the discontinuity effect: threat, $F(2,300)=12.24, p<.001$; avoid, $F(2$, $300)=26.82, p<.001$; negotiation, $F(2,300)=7.35, p=.001$; mediation, $F(2,300)=9.68, p$ $<.001$; acceptance of the other party's position, $F(2,300)=12.24, p<.001$. Based on post hoc tests $(p<.05)$, participants were more likely to report preferring to use threat with intergroup $(M=2.91, S D=1.62)$ and international conflicts $(M=3.97, S D=1.89)$ relative to interpersonal conflicts $(M=1.83, S D=1.39)$. They also preferred to use threat more with international than with intergroup conflict. Participants preferred to use avoidance more with intergroup $(M=2.92, S D=1.69)$ and international conflicts $(M=3.49, S D=1.98)$ relative to interpersonal conflicts $(M=1.81, S D=1.12)$. They also preferred to use avoidance more with international than with intergroup conflict. On the other hand, participants were more likely to report preferring to use negotiation, mediation, and acceptance with interpersonal than with either intergroup or international conflict. There were no differences in preferring negotiation, mediation, and acceptance in intergroup versus the international conflict conditions. The means on the conflict-reducing techniques for the interpersonal, intergroup, and international conflict conditions, respectively, are as follows: negotiation $(M=6.21, S D=$ $1.28 ; M=5.49, S D=1.53 ; M=5.65, S D=1.21)$, mediation $(M=5.78, S D=1.25 ; M=4.95$, $S D=1.80 ; M=4.84, S D=1.80)$, and acceptance $(M=2.97, S D=1.93 ; M=2.07, S D=1.59$; $M=1.89, S D=1.37)$.

There was also a type of conflict main effect on negative affect, $F(2,300)=13.39, p<$ .001 , but not on positive affect, $F(2,300)=1.87, n s$. Participants reported more negative affect when describing their reaction to an intergroup $(M=3.94, S D=1.37)$ or an international conflict $(M=3.89, S D=1.07)$ than to an interpersonal conflict $(M=3.14, S D=1.27)$. There was no difference in negative affect between the intergroup and the international conflict conditions.

\section{SELF-CONSTRUAL AND DISCONTINUITY}

We examined the moderating effects of self-construal on reactions to conflict in a series of hierarchical multiple regression analyses. These analyses allowed us to test for interactions of type of conflict and interdependent construal while controlling for country of origin. The predictor variables were entered into a regression equation in the following order: Type of conflict, a categorical variable, was entered in Step 1 via a dummy coding procedure. Interpersonal conflict was designated as the comparison group. The first dummy variable (C1) compares intergroup conflict (assigned a value of 1) with the interpersonal conflict group (assigned a value of 0 ). The second dummy variable (C2) compares international conflict (assigned a value of 1 ) with the interpersonal conflict group (assigned a value of 0 ). Gender (male $=0$, female $=1$ ), independence, interdependence, and country of origin (internationalborn students $=0$, American-born students $=1$ ) were entered in Step 2. Scores on the predictor variables of independence and interdependence were centered (using deviation scores 
TABLE 1

Hierarchical Multiple Regression of Predictor Variables on Threat

\begin{tabular}{|c|c|c|c|c|c|}
\hline Hierarchical Entry of Variables & $\mathrm{t}$ & $\mathrm{p}<$ & $\beta$ & $\Sigma \mathrm{R}^{2}$ & $\Delta \mathrm{R}^{2}$ \\
\hline 1. $\mathrm{C} 1$ & 4.88 & .001 & .27 & & \\
\hline $\mathrm{C} 2$ & 9.11 & .001 & .50 & .221 & .221 \\
\hline 2. Gender & -1.70 & $n s$ & -.08 & & \\
\hline Independence & -0.14 & $n s$ & -.01 & & \\
\hline Interdependence & -1.95 & $n s$ & -.21 & & \\
\hline Origin & 0.77 & $n s$ & .04 & .251 & .030 \\
\hline 3. Origin $\times$ Independence & 0.00 & $n s$ & .00 & & \\
\hline Origin $\times$ Interdependence & 1.01 & $n s$ & .07 & .253 & .002 \\
\hline 4. $\mathrm{C} 1 \times$ Independence & -0.30 & $n s$ & -.02 & & \\
\hline $\mathrm{C} 2 \times$ Independence & 1.99 & $n s$ & .13 & .268 & .015 \\
\hline 5. $\mathrm{C} 1 \times$ Interdependence & 1.83 & $n s$ & .12 & & \\
\hline $\mathrm{C} 2 \times$ Interdependence & 5.52 & .001 & .39 & .340 & .072 \\
\hline $\begin{array}{l}F(12,293)=12.56, p<.001 \\
R^{2}=.340\end{array}$ & & & & & \\
\hline
\end{tabular}

NOTE: $\mathrm{C} 1$, the first dummy-coded variable, compares intergroup conflict with the interpersonal conflict comparison group. $\mathrm{C} 2$, the second dummy-coded variable, compares international conflict with interpersonal conflict. The standardized parameter estimates $(\beta), t$-values, and $p$ values are for the full model. $d f=293$ for the $t$ tests. The $p$ value for the significance tests was set at .004 .

with their means set as 0; see Aiken \& West, 1991). The interactions of country of origin with independence and interdependence were entered in Step 3. The interactions of C1 (intergroup versus interpersonal conflict) by independence and $\mathrm{C} 2$ (international versus interpersonal conflict) by independence were entered in Step 4. Finally, the interactions of C1 by interdependence and C2 by interdependence were entered as Step 5. Seven hierarchical regressions were computed with 12 predictor variables being tested in each multiple regression analysis. To reduce the risk of Type I error, the significance level of .004 was chosen for these analyses (.05 divided by 12 tests per multiple regression).

We predicted a type of conflict by interdependence interaction on the endorsement of conflict resolution strategies: Those high, compared to those low, in interdependence are more likely to use conflict-enhancing (threat and avoidance) and less likely to use conflictreducing techniques (negotiation, mediation, and acceptance) in intergroup and international than in interpersonal disputes. We also expected that the effects of interdependence would be strongest in comparisons between international versus interpersonal disputes. These predictions were partly supported for two types of reactions to conflict: the use of threats and acceptance. As Table 1 indicates, on the threat-dependent measure, there was a significant interaction of $\mathrm{C} 2$ (international versus interpersonal conflict) by interdependence, $\beta=.39, t(293)=5.52, p<.001$. For Step 5, which includes this interaction effect, $\Delta R^{2}=$ $.072, F$ change $(2,293)=15.87, p<.001$. Plotting the interaction (Aiken \& West, 1991), those high, compared to those low, in interdependence endorsed the use of threat more in an international than in an interpersonal conflict. On the threat measure, there was no significant interaction of $\mathrm{C} 1$ (intergroup versus interpersonal conflict) by interdependence, $\beta=.12$, $t(293)=1.83, n s$ (see Figure 1). On the acceptance measure, there was also a significant interaction of $\mathrm{C} 2$ by interdependence, $\beta=-.38, t(293)=-4.82, p<.001$. For Step 5 , which 


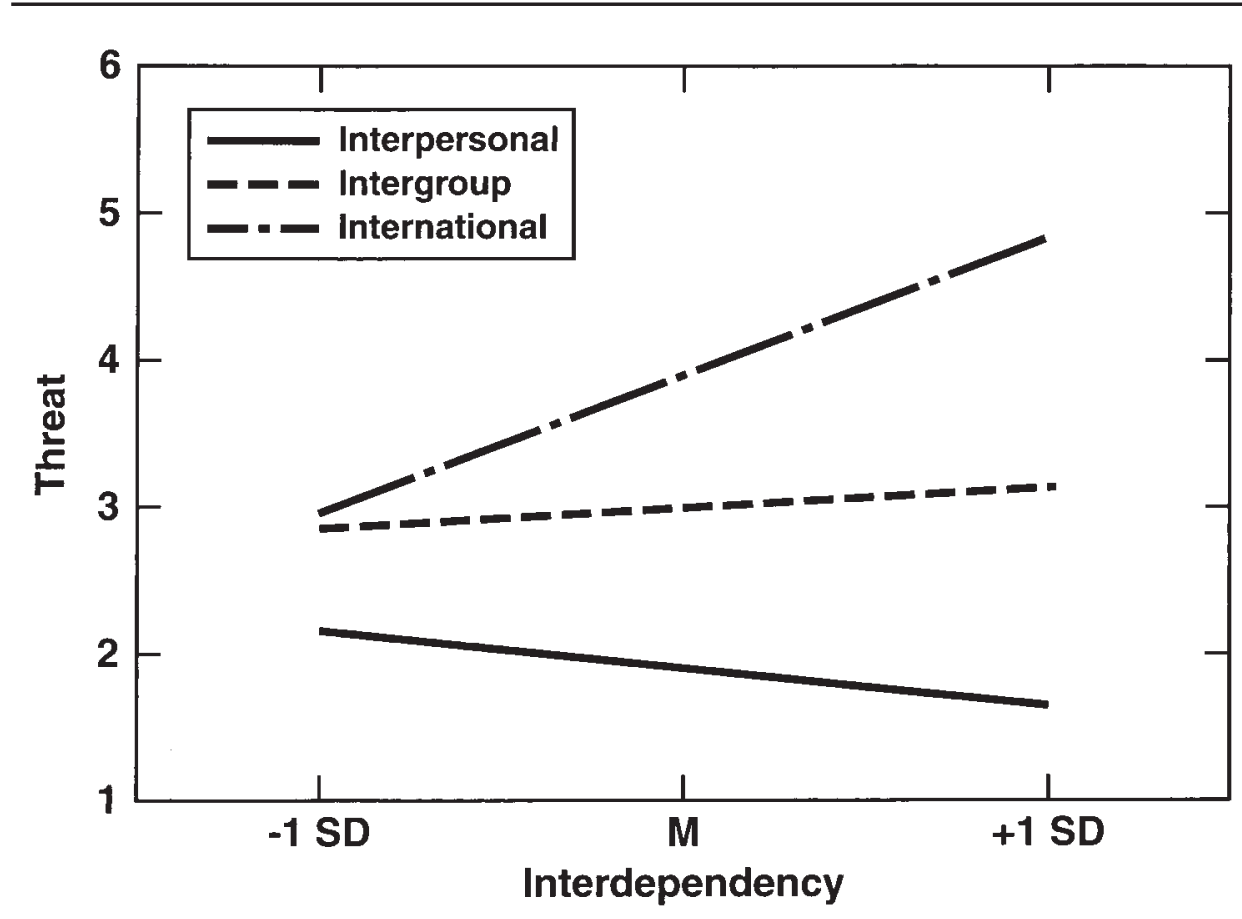

Figure 1: Simple Regression Lines Summarizing the Interaction of Type of Conflict by Interdependency on the Threat-Dependent Measure

includes this interaction effect, $\Delta R^{2}=.072, F$ change $(2,293)=12.88, p<.001$. See Table 2 for detailed results of this regression. Those high, compared to those low, in interdependence endorsed the use of acceptance more in an interpersonal conflict than in an international conflict. On the acceptance measure, there was no significant interaction of $\mathrm{C} 1$ (intergroup versus interpersonal conflict) by interdependence, $\beta=-.08, t(293)=-1.07$, $n s$ (see Figure 2). There were no significant effects in the regression equations on any of the conflict resolution strategies that incorporated the country of origin of the research participants.

For the dependent measures of negotiation, mediation, and avoiding the situation, there were no significant interactions of type of conflict by interdependence or independence.

\section{AFFECT MEASURES}

On negative affect, there were significant interactions of $\mathrm{C} 1$ (dummy coded as intergroup versus interpersonal conflict) by interdependence, $\beta=.22, t(293)=2.88, p=.004$, and C2 (dummy coded as international versus interpersonal conflict) by interdependence, $\beta=.28$, $t(293)=3.53, p<.001$. For Step 5, which includes these two interaction effects, $\Delta R^{2}=.040, F$ change $(2,293)=7.00, p=.001$. See Table 3 for the detailed results of this regression. Plotting these interactions (see Figure 3), those high, compared to those low, in interdependence felt more negative affect in intergroup and international conflict than in interpersonal conflict. There were no significant interaction effects of type of conflict by interdependence or independence on the positive affect measure. 
TABLE 2

Hierarchical Multiple Regression of Predictor Variables on Acceptance

\begin{tabular}{|c|c|c|c|c|c|}
\hline Hierarchical Entry of Variables & $\mathrm{t}$ & $\mathrm{p}<$ & $\beta$ & $\Sigma \mathrm{R}^{2}$ & $\Delta \mathrm{R}^{2}$ \\
\hline 1. C1 & -3.88 & .001 & -.24 & & \\
\hline $\mathrm{C} 2$ & -4.72 & .001 & -.29 & .077 & .077 \\
\hline 2. Gender & -0.25 & $n s$ & -.01 & & \\
\hline Independence & -1.16 & $n s$ & -.14 & & \\
\hline Interdependence & 4.54 & .001 & .54 & & \\
\hline Origin & 0.14 & $n s$ & .01 & .095 & .018 \\
\hline 3. Origin $\times$ Independence & 0.78 & $n s$ & .06 & & \\
\hline Origin $\times$ Interdependence & -2.16 & $n s$ & -.17 & .100 & .005 \\
\hline 4. $\mathrm{C} 1 \times$ Independence & 0.30 & $n s$ & .02 & & \\
\hline $\mathrm{C} 2 \times$ Independence & 0.93 & $n s$ & .07 & .103 & .003 \\
\hline 5. $\mathrm{C} 1 \times$ Interdependence & -1.07 & $n s$ & -.08 & & \\
\hline $\mathrm{C} 2 \times$ Interdependence & -4.82 & .001 & -.38 & .175 & .072 \\
\hline
\end{tabular}

$F(12,293)=5.19, p<.001$

$R^{2}=.175$

NOTE: $\mathrm{C} 1$, the first dummy-coded variable, compares intergroup conflict with the interpersonal conflict comparison group. $\mathrm{C} 2$, the second dummy-coded variable, compares international conflict with interpersonal conflict. The standardized parameter estimates $(\beta), t$-values, and $p$ values are for the full model. $d f=293$ for the $t$ tests. The $p$ value for the significance tests was set at .004 .

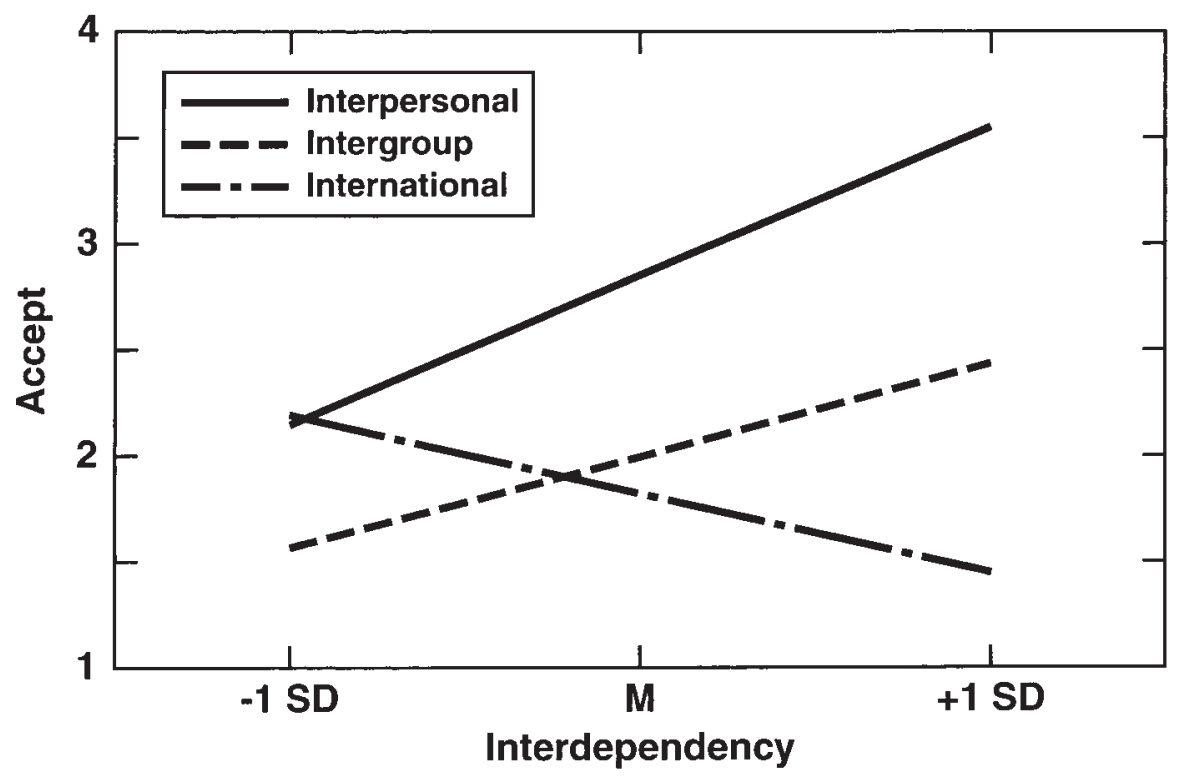

Figure 2: Simple Regression Lines Summarizing the Interaction of Type of Conflict by Interdependency on the Acceptance of the Situation-Dependent Measure

\section{DISCUSSION}

The current work sought to integrate two research traditions that have explored the nature and cause of conflict between groups. One of those traditions, based on Insko, Schopler, and 
TABLE 3

Hierarchical Multiple Regression of Predictor Variables on Negative Affect

\begin{tabular}{lccccc}
\hline \hline Hierarchical Entry of Variables & $\mathrm{t}$ & $\mathrm{p} \leq$ & $\beta$ & $\Sigma \mathrm{R}^{2}$ & $\Delta \mathrm{R}^{2}$ \\
\hline 1. C1 & 5.06 & .001 & .32 & & \\
$\mathrm{C} 2$ & 4.25 & .001 & .26 & .082 & .082 \\
2. Gender & -0.74 & $n s$ & -.04 & & \\
Independence & 0.48 & $n s$ & .06 & & \\
Interdependence & -1.30 & $n s$ & -.16 & & \\
Origin & -0.39 & $n s$ & -.02 & .117 & .035 \\
3. Origin $\times$ Independence & 0.46 & $n s$ & .04 & & \\
Origin $\times$ Interdependence & 0.61 & $n s$ & .05 & .119 & .002 \\
4. C1 $\times$ Independence & 0.03 & $n s$ & .00 & & \\
C2 $\times$ Independence & -1.12 & $n s$ & -.08 & .125 & .006 \\
5. C1 $\times$ Interdependence & 2.88 & .004 & .22 & & \\
C2 $\times$ Interdependence & 3.53 & .001 & .28 & .165 & .040
\end{tabular}

$F(12,293)=4.81, p<.001$

$R^{2}=.165$

NOTE: $\mathrm{C} 1$, the first dummy-coded variable, compares intergroup conflict with the interpersonal conflict comparison group. $\mathrm{C} 2$, the second dummy-coded variable, compares international conflict with interpersonal conflict. The standardized parameter estimates $(\beta), t$-values, and $p$ values are for the full model. $d f=293$ for the $t$ tests. The $p$ value was set at .004.

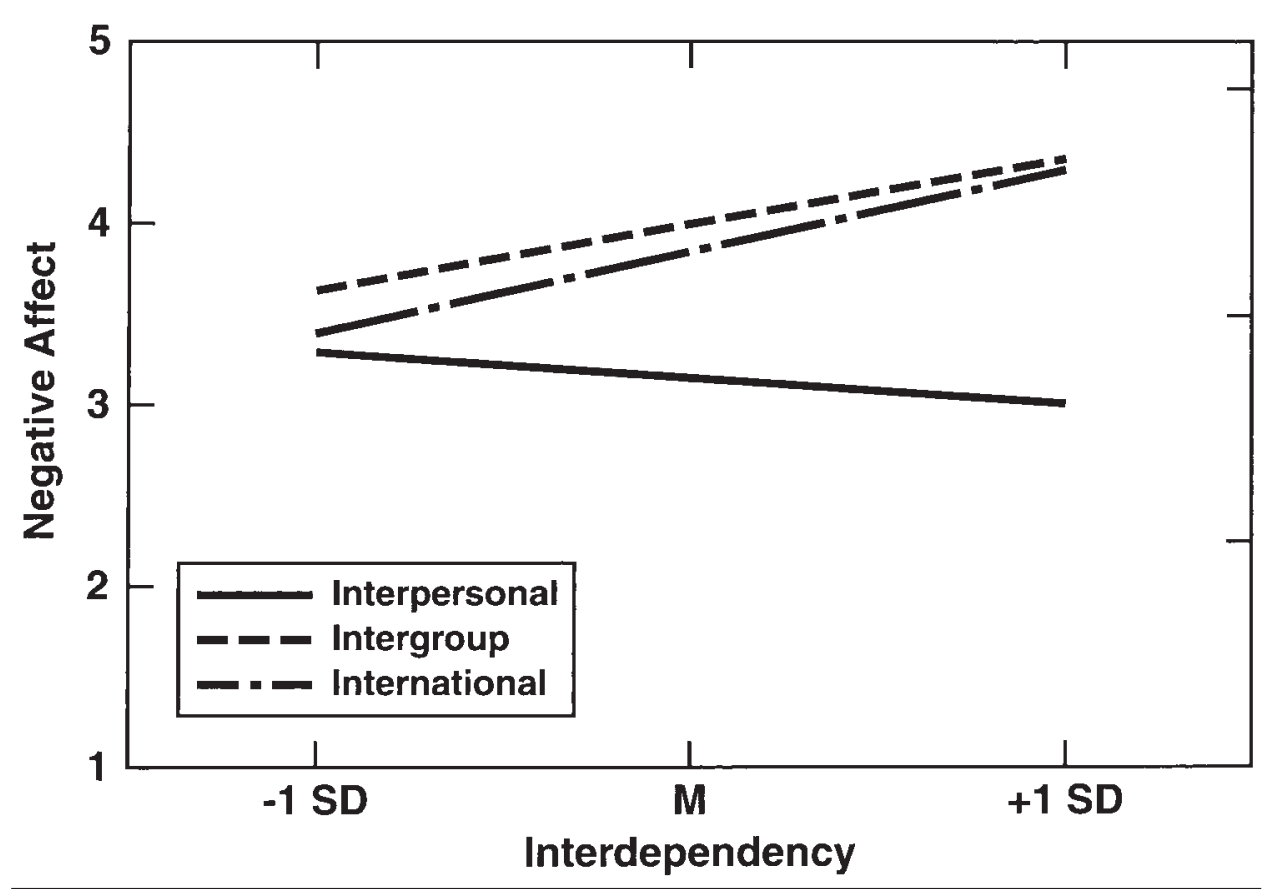

Figure 3: Simple Regression Lines Summarizing the Interaction of Type of Conflict by Interdependency on the Negative Affect Dependent Measure 
their colleagues' studies of the discontinuity effect (e.g., Insko \& Schopler, 1998), suggests that the pronounced competitiveness of groups in comparison to individuals is rooted in social support for self-seeking motives, distrust of groups, and the freeing effects of working with others. The second tradition, social identity theory, suggests that situations that bring groups into contact with one another trigger self-categorization processes that create ingroup favoritism, out-group rejection, and, ultimately, intergroup competition and conflict.

Our results, which indicate that level of interdependent self-construal moderates the intensity of individuals' reactions to intergroup conflicts, provide relatively clear support for a social identity interpretation of the roots of intergroup conflict. Interdependents should, in theory, be more likely to identify with larger groups and collectives, and such identification should trigger more negative reactions to out-groups (e.g., Hinkle \& Brown, 1990). Hence, as Brown et al. (1992) suggested, those high in interdependence - combined with a high relational orientation (emphasizing in-group versus out-group comparisons) - may be particularly susceptible to being biased (and perhaps competitive) against out-groups because of strong identification with the in-group. Although we did not directly measure in-group identification and evaluative ratings of in-groups and out-groups, our findings support the basic assumptions of social identity theory.

The overall differences in how people responded to interpersonal, intergroup, and international conflicts also support social identity theory. Interdependent construal of self had no moderating effect on the threat or acceptance measures in intergroup versus interpersonal conflict situations, suggesting that these temporary, dynamic groups do not trigger the same types of social identity processes as long-term, categorical groups (Wilder \& Simon, 1998). Hence, research participants who were high in interdependence may not have perceived sufficient distance or dissimilarity between themselves and the other party in the intergroup conflict condition to trigger higher threat or lower acceptance in that situation (see Triandis et al., 1990). Interdependent self-construal's absence of moderating effects for more moderate types of conflict resolution (i.e., negotiation, mediation, and avoidance), although not predicted, may reflect a participant's ambivalence toward such nondecisive tactics. It may be that only extreme responses-a confrontational tactic such as threat or an acquiescent tactic such as acceptance of the situation-are considered as appropriate tactics by those high in interdependence in handling relations with anyone considered extremely dissimilar or similar from oneself. Negotiation, mediation, and avoidance may be too moderate (not sufficiently confrontational or acquiescent) for those high in interdependence to be useful in distinguishing how someone should react to conflict between individuals versus between countries.

These findings are also consistent with recent theory and research about the effects of interdependence and independence on behavior in social situations. Individual differences in interdependence are expected to reflect how people perceive their "relationship between self and others" (Markus \& Kitayama, 1994, p. 570). The notion of an interdependent construal of the self (Markus \& Kitayama, 1994; Singelis, 1994, 2000) is based on the idea that people see themselves as being connected and belonging to a particular in-group. Belonging to an in-group, for those high in interdependence, may include an expectation of friendly relations and "give-and-take" in conflicting situations with in-group members but not with outgroups. On the other hand, for those low in interdependence, there may be no expectation of differences in friendly or unfriendly relationship with in-group or out-group parties-if they even make these distinctions between in-groups and out-groups (Triandis et al., 1990).

These findings also support the notion that someone high in interdependence perceives interactions between groups and between countries, compared to between individuals, as 
more competitive, unfriendly, or unsafe (Betz \& Fry, 1995; Hoyle et al., 1989; Tajfel \& Turner, 1979). Consistent with the findings on threat and acceptance, those high, compared to those low, in interdependence felt more negative affect in international than in interpersonal conflict. Also, among those high in interdependence, they felt more negative affect in intergroup than in interpersonal conflict. Additional research is necessary to determine whether those high in interdependence either believe that it is more acceptable to express negative feelings in a dispute with an out-group or another country or that they actually feel more negative in these situations.

The international participants scored higher on the interdependent construal of self, and the American participants scored higher on the independent construal of self. However, there were no effects of country of origin on the endorsement of conflict resolution strategies or on the affect measures. The success of interdependence as a moderator of the impact of type of conflict situation (and the absence of effects due to country of origin) attests to the usefulness of focusing on psychological mechanisms in understanding culture-linked phenomena (Singelis, 2000; Singelis et al., 1999). Individual differences in interdependence (that is, how much one thinks about oneself as interconnected or intertwined with an in-group; Singelis, 1994, p. 581) influences willingness to avert conflict with in-group members and to engage in conflict with out-group others, regardless of country of origin.

Limitations of the present research should be noted. Because our data were collected on a single university campus in southeastern Virginia, the results need to be replicated with other samples of research participants both in the United States and in other countries. Also, the research was conducted before the events of September 11, 2001, in the United States, when the World Trade Center in New York City and the Pentagon in Washington, DC, were attacked by hijacked planes. It would be worthwhile to see how the findings would replicate at the present time with American research participants and participants from other countries who have been affected by these events. Unlike Schopler and Insko's (1992) laboratorybased research with the Prisoner's Dilemma game, we did not have participants interacting in vivo with other individuals or with representatives of other groups or nations. The findings need to be replicated with individuals who are actually interacting with members of their own groups or countries or with members of other groups or countries.

A limitation is that we do not know the exact mechanisms that account for those high in interdependence endorsing threat in an international conflict and endorsing acceptance in an interpersonal conflict. Leung (e.g., Leung, 1987; Leung et al., 1990; Leung \& Lind, 1986) has conducted extensive research on the possible mechanisms for culture-linked preferences in solving conflicts. Perhaps those high in interdependence value conflict-enhancing strategies more in disputes between countries versus between individuals - the valence hypothesis - or they may believe that conflict-enhancing strategies have a higher probability of being successful in international disputes-the instrumentality hypothesis (Leung, 1987). Hence, follow-up research on the discontinuity effect should examine how the interdependent construal of self is related to the value placed on various conflict resolution strategies and the perceived instrumentality of these strategies in disputes between individuals and between countries. Similarly, our analysis of conflict based on social identity theory inferred but did not measure that those who are high in interdependence strongly identify with their in-group. Future research along the lines of the present study needs to directly measure identification with the in-group.

Another limitation is that the reliability estimates were low for the self-construal scales, especially for the independent construal subscale with the international students. Our failure to find results with independent self-construal, although predicted, may reflect the 
independent subscale's low reliability. Further research seems necessary on the refinement of the Self-Construal Scale so that it serves as a more reliable measure of independence and interdependence in a range of cultures.

In conclusion, the present research documents how the interdependent construal of self (controlling for the effects of country of origin) is related to the endorsement of conflict resolution strategies in interpersonal versus international disputes. It also documents that interdependence is associated with self-reports of negative feelings in disputes between individuals versus between groups or between countries. The type of social conflict by itself does not account for the selection of conflict-enhancing or conflict-reduction techniques in coping with disputes; its effects are moderated by culture-linked individual differences in construal of interdependence by the disputants.

\section{REFERENCES}

Aiken, L. S., \& West, S. G. (1991). Multiple regression: Testing and interpreting interactions. Newbury Park, CA: Sage.

Betz, B., \& Fry, W. R. (1995). The role of group schema in the selection of influence attempts. Basic and Applied Social Psychology, 16, 351-365.

Brewer, M. B., \& Brown, R. J. (1998). Intergroup relations. In D. T. Gilbert, S. T. Fiske, \& G. Lindzey (Eds.), The handbook of social psychology (4th ed., Vol. 2, pp. 554-594). New York: McGraw-Hill.

Brown, R., Hinkle, S., Ely, P. G., Fox-Cardamone, L., Maras, P., \& Taylor, L. A. (1992). Recognizing group diversity: Individualist-collectivist and autonomous-relational social orientations and their implications for intergroup processes. British Journal of Social Psychology, 31, 327-342.

Brown, R., Maras, P., Masser, B., Vivian, J., \& Hewstone, M. (2001). Life on the ocean wave: Testing some intergroup hypotheses in a naturalistic setting. Group Processes \& Intergroup Relations, 4, 81-97.

Duckitt, J., \& Mphuthing, T. (1998). Group identification and intergroup attitudes: A longitudinal analysis in South Africa. Journal of Personality and Social Psychology, 74, 80-85.

Gire, J. G. T., \& Carment, D. W. (1992). Dealing with disputes: The influence of individualism-collectivism. Journal of Social Psychology, 133, 81-95.

Hinkle, S., \& Brown, R. (1990). Intergroup comparisons and social identity: Some links and lacunae. In D. Abrams $\&$ M. Hogg (Eds.), Social identity theory: Constructive and critical advances (pp. 48-70). New York: Springer.

Hofstede, G. (1980). Culture's consequences. Beverly Hills, CA: Sage.

Howard, J. A. (2000). Social psychology of identities. Annual Review of Sociology, 26, 367-393.

Hoyle, R. H., Pinkley, R. L., \& Insko, C. A. (1989). Perceptions of social behavior: Evidence of differing expectations for interpersonal and intergroup interaction. Personality and Social Psychology Bulletin, 15, 365-376.

Hui, C. H. (1988). Measurement of individualism-collectivism. Journal of Research in Personality, 22, 17-36.

Insko, C. A., \& Schopler, J. (1998). Differential distrust of groups and individuals. In C. Sedikides, J. Schopler, \& C. A. Insko (Eds.), Intergroup cognition and intergroup behavior (pp. 75-107). Mahwah, NJ: Lawrence Erlbaum.

Insko, C. A., Schopler, J., Hoyle, R. H., Dardis, G. J., \& Graetz, K. A. (1990). Individual-group discontinuity as a function of fear and greed. Journal of Personality and Social Psychology, 58, 68-79.

Kagitcibasi, C. (1994). A critical appraisal of individualism and collectivism: Toward a new formulation. In U. Kim, H. C. Triandis, C. Kagitcibasi, S. C. Choi, \& G. Yoon (Eds.), Individualism and collectivism (pp. 55-66). Thousand Oaks, CA: Sage.

Kim, U. (1994). Individualism and collectivism: Conceptual clarification and elaboration. In U. Kim, H. C. Triandis, C. Kagitcibasi, S. C. Choi, \& G. Yoon (Eds.), Individualism and collectivism (pp. 19-40). Thousand Oaks, CA: Sage.

Leung, K. (1987). Some determinants of reactions to procedural models for conflict resolution: A cross-national study. Journal of Personality and Social Psychology, 53, 898-908.

Leung, K. (1988). Some determinants of conflict avoidance. Journal of Cross-Cultural Psychology, 19, 125-136.

Leung, K., Au, Y., Fernandez-Dols, J. M., \& Iwawaki, S. (1992). Preference for methods of conflict processing in two collectivist cultures. International Journal of Psychology, 27, 195-209.

Leung, K., Bond, M. H., Carment, D. W., Krishnan, L., \& Liebrand, W. B. G. (1990). Effects of cultural femininity on preference for method of conflict processing: A cross-cultural study. Journal of Experimental Social Psychology, 26, 373-388.

Leung, K., \& Lind, E. A. (1986). Procedure and culture: Effects of culture, gender, and investigator status on procedural preferences. Journal of Personality and Social Psychology, 50, 1134-1140. 
Markus, H. R., \& Kitayama, S. (1991). Culture and the self: Implications for cognition, emotion, and motivation. Psychological Review, 98, 224-253.

Markus, H. R., \& Kitayama, S. (1994). A collective fear of the collective: Implications for selves and theories of selves. Personality and Social Psychology Bulletin, 20, 568-579.

Oyserman, D. (1993). The lens of personhood: Viewing the self and others in a multicultural society. Journal of Personality and Social Psychology, 65, 993-1009.

Schopler, J., \& Insko, C. A. (1992). The discontinuity effect in interpersonal and intergroup relations: Generality and mediation. In W. Stroebe \& M. Hewstone (Eds.), European review of social psychology (Vol. 3, pp. 121152). Chichester, UK: Wiley.

Singelis, T. M. (1994). The measurement of independent and interdependent self-construals. Personality and Social Psychology Bulletin, 20, 580-591.

Singelis, T. M. (2000). Some thoughts on the future of cross-cultural social psychology. Journal of Cross-Cultural Psychology, 31, 76-91.

Singelis, T. M., Bond, M. H., Sharkey, W. F., \& Siu Yiu Lai, C. (1999). Unpackaging culture's influence on selfesteem and embarrassability: The role of self-construals. Journal of Cross-Cultural Psychology, 30, 315-341.

Singelis, T. M., Triandis, H. C., Bhawuk, D. P. S., \& Gelfand, M. J. (1995). Horizontal and vertical dimensions of individualism and collectivism: A theoretical and measurement refinement. Cross-Cultural Research, 29, 240-275.

Tajfel, H. (1982). The social psychology of intergroup relations. Annual Review of Psychology, 33, 1-39.

Tajfel, H., \& Turner, J. C. (1979). An integrative theory of intergroup conflict. In W. G. Austin \& S. Worchel (Eds.), The social psychology of intergroup relations (pp. 33-47). Westport, CT: Brooks-Cole.

Triandis, H. C. (1995). Individualism and collectivism. Boulder, CO: Westview.

Triandis, H. C., Bontempo, R., Villareal, M. J., Asai, M., \& Lucca, N. (1988). Individualism and collectivism: Crosscultural perspectives on self-ingroup relationships. Journal of Personality and Social Psychology, 54, 323-338.

Triandis, H. C., McCusker, C., \& Hui, C. H. (1990). Multimethod probes of individualism and collectivism. Journal of Personality and Social Psychology, 59, 1006-1020.

Turner, J. C., \& Onorato, R. S. (1999). Social identity, personality, and the self-concept: A self-categorization perspective. In T. R. Tyler, R. M. Kramer, \& O. P. John (Eds.), The psychology of the social self (pp. 11-46). Mahwah, NJ: Lawrence Erlbaum.

Watson, D., Clark, L. A., \& Tellegen, A. (1988). Development and validation of brief measures of positive and negative affect: The PANAS scales. Journal of Personality and Social Psychology, 54, 1063-1070.

Wilder, D. A., \& Simon, A. F. (1998). Categorical and dynamic groups: Implications for social perception and interpersonal behavior. In C. Sedikides, J. Schopler, \& C. A. Insko (Eds.), Intergroup cognition and intergroup behavior (pp. 27-44). Mahwah, NJ: Lawrence Erlbaum.

Valerian J. Derlega is Professor of Psychology at Old Dominion University, Norfolk, Virginia. Dr. Derlega received his B.S. degree (1966) from the City College of New York and Ph.D. in social psychology from the University of Maryland -College Park in 1971. Dr. Derlega's research interests include close relationships, self-disclosure, privacy, and social support in coping with HIV, HIV in correctional settings, and gender roles and sexual orientation. Dr. Derlega has co-edited, HIV and social interaction (Sage, 1998) and co-authored the forthcoming book, Handbook of self-disclosure and privacy in coping with HIV (Erlbaum, in press).

Cem Safak Cukur received his Ph.D. (2002) in social psychology from the University of Nebraska-Lincoln. He began a new position as assistant professor at Mugla University, Mugla, Turkey, in the fall semester 2002. His research interests are in applied social psychology (e.g., poverty and AIDS), cross-cultural differences in self and emotional processes, intergroup relations, and cross-cultural research methodology.

Jenny C. Y. Kuang received her B.A. degree (1997) from the University of California, Berkeley, in psychology and anthropology. She received her M.S. (2000) from Old Dominion University in psychology and is currently a Ph.D. candidate at Old Dominion University in industrial and organizational psychology. Among Ms. Kuang's research interests are personnel testing and selection, team performance assessment, team training, and research methods and statistical analysis.

Donelson R. Forsyth, Ph.D., is Professor of Psychology at Virginia Commonwealth University in Richmond, Virginia. He completed his undergraduate studies at Florida State University, and received a Ph.D. in social psychology in 1978 from the University of Florida and joined the faculty of Virginia Commonwealth University in that year. Dr. Forsyth studies reactions to success and failure, individual differences in moral thought, applications of social psychology in educational and clinical settings, and group dynamics. He has written and edited several books, including Our social world (1995) and Group dynamics and was founding editor of the journal Group Dynamics. 